\title{
Teachers' Disposition and Teaching Space Organisation in Public Secondary Schools, Delta State Nigeria
}

\author{
NKEDISHU, Victor Chukwubueze* AKPOREHE, Dorah A \\ Department of Educational Management and Foundations, Delta State University, Abraka, Nigeria
}

\begin{abstract}
This study examined teachers' disposition and teaching space organisation in public secondary schools, Delta State Nigeria. The study adopted correlational survey of ex-post-facto research design. The targeted population entailed 452 principals in public secondary schools, from which a sample of 226 were drawn using stratified sampling technique. Instrument titled Teachers' Disposition and Teaching Space Organisation Questionnaire (TDTSOQ) which was self-constructed was adopted in soliciting information from respondents. Face and content validity were embraced in validating the self-constructed instrument and it was subjected to a split-half reliability test using 30 principals not involved in the main study, a co-efficient of 0.77 was obtained. The data gathered were carefully converted to mean score and standard deviation to answer research questions raised at 2.50 benchmark while Pearson Product Moment Correlation Statistics was applied to test hypothesis formulated at .05 level of significance. Finding shows that teachers' disposition is related to teaching space organisation in public secondary schools, Delta State. It was recommended among others that school principals particularly in Delta State public school should constantly organise training within the school with special interest on teaching space organisation. Keywords: Teachers' Disposition, Teaching Space Organisation, Public Secondary Schools, Delta State.
\end{abstract}

DOI: $10.7176 / \mathrm{JEP} / 11-21-10$

Publication date:July $31^{\text {st }} 2020$

\section{Introduction}

The ability to direct students' conduct towards the outlined educational goals and objectives is an indicators of teachers competent and effectiveness. This simply means that teachers must be an expert in teaching profession, teaching space organiser, demonstrate acceptable leadership traits and mastery of subject area. It is a clear fact that excluding cordial teacher-students' rapport, effective teaching-learning will not take place. With reference to teaching space organisation, teacher is presumed to be a manager/leader and leadership is a way of direction and product of collaboration. Leadership is an interactive stimulus exercise in conditions and directed through communication process with the aim of attaining specific goals (Jacob, \& Herma, 2009). A robust drive for obligation and task accomplishment, persistence and vigour in pursuit of goals, uniqueness in problem solving, drive to exercise creativity in social situations, assurance and sense of special identity, readiness to accept consequences of action and decision are some characteristics of a leader (Lew 2009). According to Coats (2009) disposition approaches also interrogate the validity training of individuals to shoulder leadership positions. For leadership training to have value, individuals with intrinsic leadership disposition have to undergo such training opportunities. It entails that only individuals who have leadership disposition of a teacher should take-up teaching profession.

Ability to organise teaching space meritoriously is increasingly becoming a vital need in any quest for effective teaching-learning in educational system, globally. In Nigeria the urge is about the same as the issue of teaching space organisation has become crucial, ubiquitous, and recurring in educational discourse. In poorly managed teaching space, effective teaching-learning can hardly be noticed. A well-managed teaching space requires a teacher who is categorised by high knowledge of pedagogy, content, context, and personal conduct (Clark \& Peterson, 2006). It implies that success of teaching space organisation is dependent on teacher's personal disposition evident in their standard of perfect ethical and social conduct. The word teaching space organisation or classroom management forms a popular vocabulary in Nigeria educational context, its precise meaning in application to Nigerian Secondary Schools appears lacking and unsatisfactory. Teachers seem to have different views about what teaching space organisation ought to be, without identifiable common teaching space organisation components. Effective teaching space is therefore required for the students to study enthusiastically for the attainment of national aspiration irrespective of huge responsibilities that behove on secondary schools in country's quest for technological and socio-economic development. Teachers function is therefore not restricted to teaching as is loosely said in typical Nigeria society. Teachers are essential change agents who pilot their school structures, cherish relationships and direct their students to success (Alimi, Alabi and Ehinola, 2011).

\section{Statement of the Problem}

Studies have discovered a complication between teachers' disposition and social difficulties in teaching spaces. It has been alleged that teachers are incapable to control students' disruptive conduct and accordingly, students find it difficult to attain their academic goals. In most cases, teachers disposition seems to be related to issues of 
aggressiveness, distraction, noise, mocking at teachers, shuffling of feet to mention but a few. It therefore, become necessary that teachers must recognize students' ability and modify their disposition in teaching space organisation which invariably will result to improved students' academic attainment. Importance and efficacy of teaching space organisation have been focused by many studies, few have assessed factors such as teachers' disposition on teaching space organisation. Thus, it becomes imperative for the researcher to investigate how teachers' disposition could influence teaching space organisation in public secondary schools with special interest on Delta State Nigeria. 2.2 Purpose of the Study

This study examined teachers' disposition and teaching space organisation in public secondary schools, Delta State Nigeria. In specific, it aimed at identifying available teachers' disposition, efficient ways of organising teaching space and relationship between teachers' disposition and teaching space organisation.

2.3 Research Questions

- What are the available teachers' disposition in public secondary schools?

- What are the efficient ways of organising teaching space in public secondary schools?

- What is the nature of relationship between teachers' disposition and teaching space organisation? 2.4 Hypothesis

- The relationship between teachers' disposition and teaching space organisation is not significant.

\section{Literature Review}

For second language learning, teachers' disposition is one of the most important factors apart from students' disposition. Teachers disposition is the totality of behavioural traits peculiar to an individual. In this respect, no two individuals are alike even identical twins, (Cruickshank, Jenkins \& Metcalf, 2003). Callahan (2006) explained that disposition is a dynamic organisation of those traits, characteristic patterns, and behaviour that are exceptional to individual. It is the performance of behaviour, emotions and minds of each person which influence environment (Tungehitsomkid, 2011). Knowledge, enthusiasm, warmth and humour, credibility, encouragement and supportive were good teachers' disposition which affect the learners in the classroom (Kongkiat 2013). Teacher apply body and interesting language to encourage and communicate with their students. Genuine interest in the subject, vigour and positive energy are components of teacher enthusiasm (Hamachek, 2010). Tungehitsomkid, (2011) mentioned sense of humour as one of the aspect that is important in the teaching space organisation. The overall findings and researches present that positive attitudes and motivation are relevant to achievement in second language acquisition (Lightbown \& Spada, 2013).

Berliner (2008) stated that teaching space organisation includes all those essential activities which are important to maintain an environment which generates necessary and positive conditions for learning. Carter and Carter (2011) argue that there are three goals of teaching space organisation, first, to create and maintain a highly supportive learning environment and second, to promote a safe classroom community so that students' interest, motivation and involvement in the learning process is maintained. And third, is that students are allowed to establish relationships openly and to set targets for themselves. Teachers with highly practical vision, strategies, skills and knowledge can manage teaching space effectively (Tan, 2013). Omar, (2014) explained that teaching space organisation is the process and technique by which a teacher gets his/her students or students to cooperate in directing actions towards achieving the atmosphere in the classroom, she continued that a disciplined classroom is always a good classroom. Yell and Rozalski (2008) discovered that teaching space organisation, discipline and law must yield to the needs of persons with disabilities. Set of guidelines and punishments for majority may not be applicable to individualized educational plan of some persons. Omomia and Omomia (2014) found that teachers who are efficient in teaching space organisation will involve activities in all spheres of their job as planned guidelines and processes which are judiciously and scientifically taught to students. Rahimi, Fatemeh, \& Rajaee. (2015) found that students were rewarded and praised for good conduct by EFL teachers and teachers are not very strict.

It is believed that teachers know about teaching and learning and the nature of the expectations they hold for students also exert a powerful influence on teaching space organisation, (Koko 2002). Awotua-Efebo (2007) pointed out that students who are motivated and involved in the learning process tend to do well in their academic work. This implies that they are not likely to misbehave in the classroom. Andabai and Basuo (2013) in his study reveals that the extent which teachers' disposition affects students' motivation is low. The author further discovered a positive relationship between teacher disposition and learning. Teachers' disposition does not affect classroom discipline but does affect teacher-student relationship. Significant correlation between teachers' educational level and teaching space organisation was revealed by Mohammad and Rahil, (2013). Pallvi (2017) revealed that teacher trainees taught using teaching space organisation skills as parameter of disposition development module accomplished more teacher efficiency than students taught using traditional strategies. Esiekpe (2017) revealed a substantial connection between teachers' disposition and teaching space organisation. 


\section{Method}

The study adopted correlational survey of ex-post-facto research design. The targeted population entailed 452 principals in public secondary schools, from which a sample of 226 were drawn using stratified sampling technique. Instrument titled Teachers' Disposition and Teaching Space Organisation Questionnaire (TDTSOQ) which was self-constructed was adopted in soliciting information from respondents. The instrument contains 26 items of 13 each for teachers' disposition and teaching space organisation, which respondents were required to rate their preferred options using scale of $\mathrm{SA}=4, \mathrm{~A}=3, \mathrm{D}=2$, and $\mathrm{SD}=1$. Face and content validity were adopted in validating the self-constructed instrument. To ensure that the instrument measured considerably and consistently what it intended to measure, it was subjected to a split-half reliability test using 30 principals not involved in the main study and a co-efficient of 0.77 was obtained. The data gathered were carefully converted to mean rating and standard deviation to answer research questions raised at 2.50 benchmark while Pearson Product Moment Correlation Statistics was applied to test hypothesis formulated at .05 level of significance.

\section{Results Presentation}

Research Question 1: What are the available teachers' disposition in public secondary schools?

Table 1: Mean rating and SD on available teachers' disposition in public secondary schools

\begin{tabular}{|c|l|l|l|l|}
\hline S/N & Available Teachers' Disposition & Mean & SD & Remark \\
\hline 1. & Physical appearance & 2.97 & .83 & Agree \\
\hline 2. & Enthusiasm & 2.94 & .80 & Agree \\
\hline 3. & Credibility & 3.00 & .81 & Agree \\
\hline 4. & Knowledge of subject & 2.99 & .81 & Agree \\
\hline 5. & Encouragement & 2.97 & .81 & Agree \\
\hline 6. & Sense of humour & 2.95 & .81 & Agree \\
\hline 7. & Intelligence & 2.96 & .83 & Agree \\
\hline 8. & Discipline & 3.07 & .81 & Agree \\
\hline 9. & Effective communication & 2.91 & .80 & Agree \\
\hline 10. & Temperament & 2.98 & .81 & Agree \\
\hline 11. & Organization & 2.96 & .84 & Agree \\
\hline 12. & Mutual teacher/student relationship & 3.02 & .82 & Agree \\
\hline 13. & Sensitivity to issues & 2.97 & .81 & Agree \\
\hline
\end{tabular}

Data in Table 1 shows mean rating on available teachers' disposition in public secondary schools. Result shows that respondents agree on all items with mean rating above 2.50. Conclusively, teachers disposition in public secondary schools include; physical appearance, enthusiasm, credibility, knowledge of subject, encouragement, sense of humour, intelligence, discipline, effective communication, temperament, organization, mutual teacher/student relationship and sensitivity to issues.

Research Question 2: What are the efficient ways of organising teaching space in public secondary schools? Table 2: Mean rating and SD on efficient ways of organising teaching space in public secondary schools

\begin{tabular}{|r|l|l|l|l|}
\hline S/N & Efficient ways of organising teaching space & Mean & SD & Remark \\
\hline 1. & Creating an atmosphere that allows students to learn without disruptions & 2.98 & .82 & Agree \\
\hline 2. & Classroom where respect for teachers and students are heard & 2.96 & .80 & Agree \\
\hline 3. & Teaching space that support students learning needs & 2.95 & .83 & Agree \\
\hline 4. & Teaching space that reduces poor conduct & 2.99 & .82 & Agree \\
\hline 5. & Classroom where students focused on learning & 2.99 & .81 & Agree \\
\hline 6. & Teaching space that enables social development & 2.89 & .81 & Agree \\
\hline 7. & Teaching space that facilitates emotional development & 2.94 & .82 & Agree \\
\hline 8. & Classroom that promotes positive interactions & 3.01 & .84 & Agree \\
\hline 9. & Teaching space that encourage students' participation & 2.96 & .81 & Agree \\
\hline 10. & Classroom where students understands what is expected of them & 2.83 & .79 & Agree \\
\hline 11. & Teaching space where more time is focused on teaching-learning & 2.96 & .82 & Agree \\
\hline 12 & Orderly arrangement of students desk & 2.71 & .81 & Agree \\
\hline 13. & Atmosphere where students have interest of learning & 2.84 & .82 & Agree \\
\hline
\end{tabular}

Data in Table 2 shows mean rating on efficient ways of organising teaching space in public secondary schools. Result shows that respondents agree on all items with mean rating above 2.50. It therefore means that efficient ways of organising teaching space in public secondary schools are through creating an atmosphere that allows students to learn without disruptions, classroom where respect for teachers and students are heard, classroom where students focused on learning, classroom that promotes positive interactions, classroom where students understands what is expected of them, teaching space that support students learning needs, teaching space that reduces poor conduct, teaching space that enables social development, teaching space that facilitates emotional development, 
teaching space that encourage students' participation, teaching space where more time is focused on teachinglearning, orderly arrangement of students' desk and atmosphere where students have interest of learning.

Research Question 3: What is the nature of relationship between teachers' disposition and teaching space organisation?

Table 3: Mean rating and SD on nature of relationship between teachers' disposition and teaching space organisation

\begin{tabular}{|l|l|l|l|l|}
\hline Variables & Mean & SD & r & $\mathbf{r}^{\mathbf{2}}$ \\
\hline Teachers' disposition & 38.92 & 2.80 & \multirow{2}{*}{.751} & \multirow{2}{*}{.564} \\
\cline { 1 - 4 } Teaching space organization & 32.83 & 3.92 & & \\
\hline
\end{tabular}

Data in Table 3 shows mean rating and SD on nature of relationship between teachers' disposition and teaching space organisation. Result shows mean rating of $38.92, \mathrm{SD}=2.80$ for teachers' disposition and mean rating of $32.83, \mathrm{SD}=3.92$ for teaching space organisation. r-value of .751 shows a positive relationship between teachers' disposition and teaching space organisation. $\mathrm{r}^{2}$ shows that teachers' disposition predicts teaching space organisation by $56.4 \%$

Hypothesis 1: The relationship between teachers' disposition and teaching space organisation is not significant. Table 4: Pearson (r) Analysis of teachers' disposition and teaching space organisation

\begin{tabular}{|ll|l|l|}
\hline \multicolumn{2}{|c|}{} & Teachers' disposition & Teaching space organisation \\
\hline Teachers' disposition & Pearson Correlation & 1 & $.751^{*}$ \\
& Sig. (2-tailed) & & .382 \\
& $\mathrm{~N}$ & 226 & 226 \\
\hline Teaching space organisation & Pearson Correlation & $.751^{*}$ & 1 \\
& Sig. (2-tailed) & .382 & \\
& $\mathrm{~N}$ & 226 & 226 \\
\hline
\end{tabular}

*. Correlation is significant at .05 level (2-tailed).

According to Table 3 above, the relationship between teachers' disposition and teaching space organisation shows that a strong positive relationship between teachers' disposition and teaching space organisation with $\mathrm{r}=.751$ and significance $\mathrm{P}=.382$. Therefore, relationship between teachers' disposition and teaching space organisation is significant.

\section{Discussion of Results}

Findings show that teachers disposition in public secondary schools include; physical appearance, enthusiasm, credibility, knowledge of subject, encouragement, sense of humour, intelligence, discipline, effective communication, temperament, organization, mutual teacher/student relationship and sensitivity to issues. This finding supports Callahan (2006) who stated that disposition is a dynamic organisation of those traits, characteristic patterns, and behaviour that are exceptional to individual. Kongkiat (2013) who identified knowledge, enthusiasm, warmth and humour, credibility, encouragement and supportive were good teachers' disposition which affect the learners in the classroom. Tungehitsomkid, (2011) who mentioned sense of humour as one of the aspect that is important in the teaching space.

Findings show that efficient ways of organising teaching space in public secondary schools are through creating an atmosphere that allows students to learn without disruptions, classroom where respect for teachers and students are heard, students focused on learning, promotes positive interactions, students understands what is expected of them, teaching space that support students learning needs, reduces poor conduct, enables social development, facilitates emotional development, encourage students' participation, where more time is focused on teaching-learning, orderly arrangement of students' desk and atmosphere where students have interest of learning. This finding supports Berliner (2008) who stated that teaching space organisation includes all those essential activities which are important to maintain an environment which generates necessary and positive conditions for learning. Yell and Rozalski (2008) who discovered that teaching space organisation, discipline and law must yield to the needs of persons with disabilities. Set of guidelines and punishments for majority may not be applicable to individualized educational plan of some persons. Omomia and Omomia (2014) who found that teachers who are efficient in teaching space organisation will involve activities in all spheres of their job as planned guidelines and processes which are judiciously and scientifically taught to students.

Findings show that relationship between teachers' disposition and teaching space organisation is significant. This finding concurs with Mohammad and Rahil, (2013) who discovered a significant correlation between teachers' educational level and teaching space organisation. Pallvi (2017) who revealed that teacher trainees taught using teaching space organisation skills as parameter of disposition development module accomplished more teacher efficiency than students taught using traditional strategies. Esiekpe (2017) who revealed a substantial connection between teachers' disposition and teaching space organisation. 


\section{Conclusion}

Teachers' disposition influences teaching space organisation in public secondary schools, Delta State. This is obvious since teachers who display disposition such as physical appearance, enthusiasm, credibility, knowledge of subject, encouragement, sense of humour and intelligence will promote students' learning will influence teaching space organisation.

\section{Recommendations}

- School principals particularly in Delta State public school should constantly organise training within the school with special interest on teaching space organisation.

- Teachers should appear decent within the school and in classroom.

- Teachers should be intelligent, knowledgeable and master their subject in order to create a positive teaching space organisation.

- Teachers should be display enthusiasm, credibility, encouragement and develop sense of humour which could enable them create an atmosphere that allows students to learn without disruptions.

\section{References}

Alimi, O. S. Alabi, F. O. and Ehinola, G. B. (2011). Teacher's perception of principal leadership effectiveness in public and private secondary schools in Ondo State. Global Journal USA (12) 22-27.

Andabai P. W., and Basuo, B. K., (2013) Teacher's personality and classroom management of tertiary institutions in Nigeria: The issues and perspectives. Academic Journal of Interdisciplinary Studies, 3(6), 113-118.

Awotua-Efebo E. B. (2007). Effective teaching: Principles and practice. Paragraphs.

Berliner D. C. (2008), Handbook of educational psychology (Pp. 673-708). New York: Macmillan Library

Callahan, S. G. (2006) Successful teaching in secondary schools, in teaching and the teachers' personality.

Carter, L. and Carter, M. (2011) Assertive discipline: Positive behaviour management for today's classrooms. 3rd Ed. Seal Beach, CA: Canter.

Clark, C. M., and Peterson, P. L., (2006), Teachers' thought processes. In handbook of research on teaching, Ed. Merlin C. Wittrock. New York: Macmillan.

Coats, W. D. (2009). Student perceptions of teacher: A factor analytic study. Paper presented the American educational research association convention.

Crulekshank, D. R., Jenkins, D. B., and Metcalf, K. K. (2003), The act of teaching. 3rd Ed Mcgraw-Hill

Esiekpe, J. V. (2017). Influence of teachers' personality on classroom management in Delta State public secondary schools. Unpublished Dissertation of Delta State University.

Hamachek, D. E. (2010) Psychology in teaching, learning and growth. 4th Ed Allyn and Bacon

Jacob, A. A, and Herma, J. L. (2009) Psychoanalysis. Microsoft Encarta (DVD). Redmond, W. A: Microsoft Corporation.

Koko, M. N. (2002). Organizational behaviour: Concept and dimension. Bengray Publishing Company. Port Harcourt

Kongkiat K, (2013) The practice of English language teaching 3rd impression, China Longman.

Lew, W. J. F. (2009). Teaching and teacher personality. Retrieve 2nd June, 2020.

Lightbown, P. M. and Spada, N. (2013), How language is learned, 7th impression, China Oxford University Press

Mohammad, A., and Rahil, D., (2013). On the relationship between efficacy of classroom management, transformational leadership style, and teachers' personality. Procedia - Social and Behavioural Sciences 93 (2013) $1716-1721$.

Omar, E. H. (2014). Improving the quality of learning: Global education as a vehicle for school reform. Theory into practice 39(2): 97-103.

Omomia O, Omomia T. A., (2014) Impact of classroom management on effective teaching: A study of five schools in education. European Scientific Journal. (10):22

Pallvi, P., (2017). Effect of classroom management skills as a parameter of personality development module on teacher effectiveness of teacher trainees in relation to internal locus of control. International Journal of Advanced Educational Research, 2(6); 291-294.

Rahimi M, Hosseini F. K, Rajaee, Shahid (2015). The role of teachers' classroom discipline in their teaching effectiveness and students' language learning motivation and achievement. Iranian Journal of Language Teaching Research. 3(1):57-82

Tan, O. S. (2013). Educational psychology: A practitioner-researcher approach. Australia: Thomson.

Tungehitsomkid, W. (2011) Education and teaching. Bangkok Ocean-Store

Yell M. L. and Rozalski M. E. (2008). The impact of legislation and litigation on discipline and student behaviour in the classroom. Preventing School Failure. 52(3):7-16. 